Marine Biology 86, 199-202 (1985)

\title{
Cephalopods in the diets of Emperor and Adelie penguins in Adelie Land, Antarctica
}

\author{
C. Offredo ${ }^{1}$, V. Ridoux ${ }^{1}$ and M.R. Clarke $^{2}$ \\ 1 Laboratoire d’Océanographie Biologique, Université de Bretagne Occidentale; F-29283 Brest cédex, France \\ 2 The Marine Biological Association of the United Kingdom, The Laboratory; Citadel Hill, Plymouth PL1 2PB, England
}

\begin{abstract}
Cephalopod remains were collected from all of 12 dead Emperor penguin chicks [Aptenodytes forsteri (Gray)], from $76 \%$ of 29 living adult Emperor penguins, and from 18\% of 105 living adult Adelie penguins [Pygoscelis adeliae (Hombron \& Jacquinot)] from Adelie Land, Antarctica, in 1982. Of the seven species of squids represented by lower beaks, Psychroteuthis glacialis comprised $88 \%$ of the number in both Emperor chicks and Emperor adults and 100\% in Adelie adults. From estimates of the weight of squids represented by lower beaks, Gonatus antarcticus and Kondakovia longimana contributed 18 and 14\%, respectively, of the weight of squids in the diet of Emperor chicks and 27 and $21 \%$, respectively, in the diet of Emperor adults. The data suggest that Psychroteuthis glacialis probably hatch in July-September and grow steadily for one year, and then spawn and die.
\end{abstract}

\section{Introduction}

Little is known of the food of the Emperor penguin Aptenodytes forsteri (Gray), except that it eats cephalopods (Stonehouse, 1967; Emison, 1968), or of the importance of cephalopods in the diet of the Adelie penguin Pygoscelis adeliae (Hombron \& Jacquinot). One of the authors (C.O.) was able to collect stomach contents from Emperor penguins and from Adelie penguins in Adelie Land on the Antarctic Continent during a stay from December 1981 to 7 March, 1983. This study presents the first description of the diet of birds living in Adelie Land and the first detailed description of the cephalopod contribution to the diet of Emperor and Adelie penguins. The analysis is of particular interest, since it shows which cephalopods live at high latitudes in the Antarctic $\left(66^{\circ} \mathrm{S}\right)$ and in a sector of the Antarctic (near $140^{\circ} \mathrm{E}$ ) in which there has been little collection of cephalopods (Roper, 1969) and no study of birds' diets. The study of cephalopods in the diet of sea birds in the Antarctic has relevance to studies of the biomass of cephalopods in the region (Clarke, 1983). Penguins have been estimated, on fragmentary evidence, to consume $82 \%$ of the total cephalopods eaten by all birds in the Antarctic (Mougin and Prévost, 1980; Prévost, 1981). Adelie penguins are by far the most numerous and widespread of all penguins, and their consumption of cephalopods must be very considerable.

\section{Materials and methods}

On 10th September 1982, the stomach contents of twelve Emperor penguin chicks, [Aptenodytes forsteri (Gray)], all 5 to 6 wk old and killed during a blizzard the previous night, were collected by dissection. Between 20 September and 15 November 1982, a total of 29 stomach contents of living adult Emperor penguins were collected by washing out the stomachs with 5 litres of fresh water, administered in four doses by funnel and tube, according to the technique of J. C. Stahl and H. Weimerkirsch (personal communication).

During January and February 1982, the stomach contents of 105 living adult Adelie penguins [Pygoscelis adeliae (Hombron \& Jacquinot)] were collected, and 19 of these were subsequently found to contain cephalopod remains. Most of the latter were collected after the end of January.

The cephalopod remains included, besides unidentifiable flesh, some mandibles or "beaks" and a few arm crowns. The lower beaks were identified by methods described elsewhere (Clarke, 1980, 1985). The lower rostral lengths (LRL) of the beaks were measured with vernier calipers to an accuracy of $0.05 \mathrm{~mm}$. LRL distributions of the most numerous genera and the size at which the wings of the beaks become darkened were used in comparison with 
previously described collections of beaks. Previously published (Clarke, 1985) LRL to wet weight of squid relationships were used to calculate the percentage weights of species in the diet, except in the case of Psychroteuthis glacialis, for which no curves have been published. Data from seven complete individuals collected from the present samples of $P$. glacialis revealed the relationship between total wet weight and LRL to be $\log \mathrm{wt}(\mathrm{g})=$ $2.69 \log$ LRL $(\mathrm{mm})-0.298, r=0.98$. Although this curve gives only a first approximation of the relationship, it is based upon the only material available of this very rarely caught squid and cannot, at present, be improved. From measurements of six squid from these samples together with two squid reported by Filippova (1972) and three squid referred to by Clarke (1985) the relationship between mantle (body) length (ML) and LRL was calculated to be $\log M L(\mathrm{~cm})=1.409 \log \mathrm{LRL}(\mathrm{mm})+0.236, r=0.97$. The relationship between mantle length (ML) and the length of the third arm (A) is ML (cm) $=2.195 \mathrm{~A}(\mathrm{~cm})$ $-2.518 r=0.989$; this is sometimes of use in determining the size of the squid when only crowns of arms survive digestion.

\section{Results}

Emperor penguins (Aptenodytes forsteri)

A total of 41 samples were examined, of which all but two contained cephalopod remains. There were some remains of fish (Offredo, in preparation). Because the food composition of the chicks differed in some ways from that of the adults, we shall consider them separately.

\section{Chicks}

The 12 chicks were five or six weeks old, and perished on the night of 9 September 1982. All the stomachs contained small stones, eye lenses and cephalopod beaks. The lower beaks belong to six genera in six families of squids (Table 1). All the samples contained Psychroteuthis which at present only embraces the single species $P$. glacialis Thiele, 1920. This genus comprised $88.5 \%$ of all beaks and was estimated from the LRLs to contribute $68 \%$ of the cephalopod diet by weight.

One small beak was possibly the same species as several beaks collected from adult Emperor penguins; one of these beaks was from a crown which had tentacles with many rows of suckers arranged in a similar way to those of Brachioteuthis. However, it does not appear to be the same as B. picta Chun, 1910 or B. riisei (Steenstrup, 1882) or the other Antarctic genera with multiple rows of suckers on the tentacle, and when more material becomes available it may prove to be a species new to science.

Gonatus antarcticus Lönnberg, 1898 occurred in $42 \%$ of the stomachs and, although it only represented $8.3 \%$ of the number of lower beaks, because individuals were larger than most of the other species, it contributed $17.7 \%$ of the weight represented by beaks. Similarly, the Kondakovia

Table 1. Cephalopods in samples from stomachs of chicks and adults of the Emperor penguin $A p$ tenodytes forsteri and of adults of the Adelie penguin Pygoscelis adeliae. Values are the number and percentage of samples containing remains of each species/genus of cephalopod, the number and percentage of squid lower beaks of each genus, and the estimated wet weights of each genus represented by lower beaks

\begin{tabular}{|c|c|c|c|c|c|c|c|}
\hline \multirow{2}{*}{$\begin{array}{l}\text { Cephalopod } \\
\text { species }\end{array}$} & \multicolumn{2}{|c|}{ Sample } & \multicolumn{2}{|c|}{ Beaks } & \multicolumn{3}{|c|}{ Estimated wt } \\
\hline & No. & $\%$ & No. & $\%$ & $\begin{array}{l}\text { Mean } \\
(\mathrm{g})\end{array}$ & $\begin{array}{l}\text { Total } \\
(\mathrm{g})\end{array}$ & $\begin{array}{l}\text { Total } \\
(\%)\end{array}$ \\
\hline \multicolumn{8}{|l|}{ Emperor chicks $(n=12)$} \\
\hline Psychroteuthis glacialis & 12 & 100 & 170 & 88.5 & 68 & 11455 & 68.0 \\
\hline Brachioteuthis? & 1 & 8 & 1 & 0.5 & 5 & 15 & 0.1 \\
\hline Gonatus antarcticus & 5 & 42 & 16 & 8.3 & 186 & 2980 & 17.7 \\
\hline Kondakovia longimana & 3 & 25 & 3 & 1.6 & 766 & 2297 & 13.6 \\
\hline Pholidoteuthis? & 1 & 8 & 1 & 0.5 & 71 & 71 & 0.4 \\
\hline Galiteuthis glacialis & 1 & 8 & 1 & 0.5 & 22 & 22 & 0.1 \\
\hline Totals & 12 & & 192 & 99.9 & & 16840 & 99.9 \\
\hline \multicolumn{8}{|l|}{ Emperor adults $(n=29)$} \\
\hline Psychroteuthis glacialis & 22 & 76 & 128 & 88.3 & 10 & 1316 & 50.6 \\
\hline Brachioteuthis? & 6 & 21 & 9 & 6.2 & 3 & 26 & 1.0 \\
\hline Gonatus antarcticus & 3 & 10 & 4 & 2.1 & 174 & 694 & 26.7 \\
\hline Kondakovia longimana & 1 & 3 & 1 & 0.7 & 535 & 535 & 20.6 \\
\hline Histioteuthis B & 2 & 7 & 2 & 1.4 & 16 & 31 & 1.2 \\
\hline Unidentified & 1 & 3 & 2 & 1.4 & - & - & - \\
\hline Totals & 27 & & 146 & 100.1 & & 2602 & 100.1 \\
\hline \multicolumn{8}{|l|}{ Adelie adults $(n=105)$} \\
\hline Psychroteuthis glacialis & 19 & 18 & 54 & 100 & 13.9 & 749 & 100.00 \\
\hline
\end{tabular}




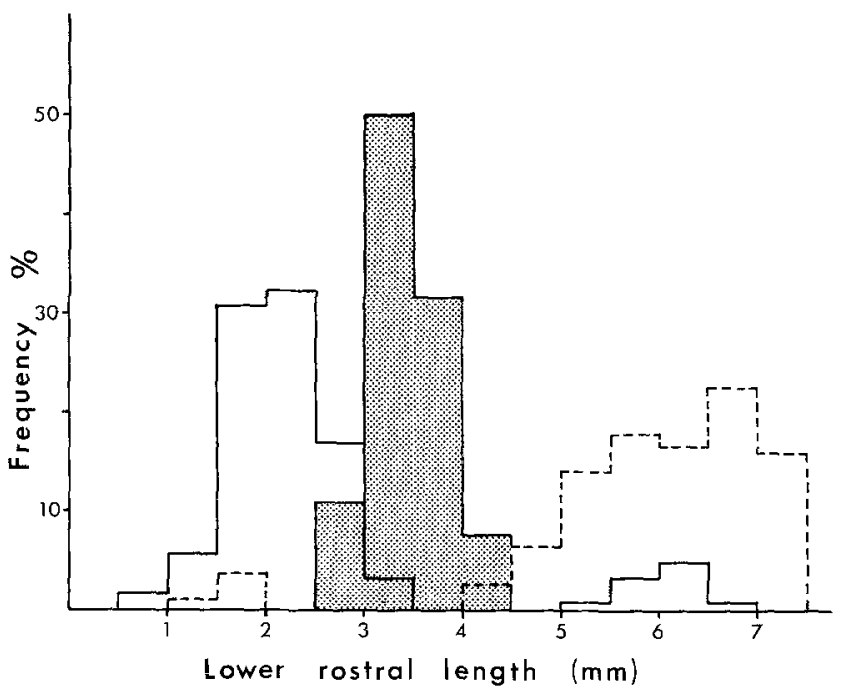

Fig. 1. Psychroteuthis glacialis. Percentage frequency distributions of the lower rostral length of squid beaks collected from Emperor penguin chicks, Aptenodytes forsteri (dashed line), in September and adults in September to November (continuous line), and from adult Adelie penguins, Pygoscelis adeliae, in January and February (stippled)

longimana Filippova, 1972 eaten were large and contributed $13.6 \%$ of the weight but only $1.6 \%$ of the number of beaks. A small beak closely resembling a small Pholidoteuthis of more temperate seas may represent another as yet undescribed species.

The largest squids taken were estimated to have a total wet weight of $766 \mathrm{~g}$ and the smallest only $1.5 \mathrm{~g}$.

The LRL distribution for Psychroteuthis glacialis from the chicks shows a small peak at 1.0 to $2.0 \mathrm{~mm}$ and a second much larger peak at 4.0 to $7.5 \mathrm{~mm}$ (Fig. 1).

\section{Adults}

Of 29 living adult samples, 27 contained cephalopod remains (Table 1); $76 \%$ of these contained Psychroteuthis glacialis, which comprised $88.3 \%$ of the beaks, and estimates show that the species contributed $50.6 \%$ of the wet weight of cephalopods represented by lower beaks. Gonatus antarcticus only comprised $2.1 \%$ of the beaks present but, because they were large, they contributed $26.7 \%$ to the weight, and the squid which provided the single Kondakovia longimana beak contributed $20.6 \%$ to the weight of cephalopods represented by beaks.

The estimated mean weight of the Psychroteuthis glacialis was much less $(10 \mathrm{~g})$ in the adult penguins than in the chicks $(68 \mathrm{~g})$, reflecting the very different LRL distributions of the beaks (Fig. 1). In the adults, most of the beaks were between LRLs of 0.5 and $3.5 \mathrm{~mm}$, with a much smaller number at 5.0 to $7.0 \mathrm{~mm}$.

Four squid species were common to both chicks and adults but, in addition, the chicks contained Pholidoteuthis? and Galiteuthis glacialis and the adults contained Histioteuthis B beaks, which are probably $H$. eltaninae Voss, 1969.
A tentacle club of a squid identified as belonging to Psychroteuthis glacialis Thiele, 1921 was found on the ground in the rookery.

\section{Adelie penguins (Pygoscelis adeliae)}

Of 105 living Adelie penguins sampled, only 19 contained the remains of cephalopods. By weight, $79 \%$ of the food was euphausiid, $18 \%$ was fish and 3\% was cephalopod (Offredo, in preparation). Two samples were taken every day from 2 January 1982 to 25 February 1982 except in bad weather conditions. No cephalopods were present in the stomachs until 25 January, and, after that 19 of 54 samples (35.2\%) contained cephalopods. All the cephalopods present were Psychroteuthis glacialis; the estimated mean weight of squids represented by beaks was $13.9 \mathrm{~g}$ and the maximum weight was $25 \mathrm{~g}$.

The LRL distribution falls between the distribution of beaks from the Emperor penguin stomachs (Fig. 1).

\section{Cephalopod growth}

Psychroteuthis glacialis lower beaks with undarkened wings had LRLs of 1.9 to $4.2 \mathrm{~mm}$ and beaks with darkened wings had LRLs of 3.2 to $7.3 \mathrm{~mm}$. One beak was in the intermediate stage, an isolated dark spot on the wing, at a LRL of $3.9 \mathrm{~mm}$. Thus, darkening of the wing takes place at 3.2 to $4.2 \mathrm{~mm}$. This stage takes place prior to sexual maturity in many species, and beaks which have undarkened wings are immature in nearly all species. From Fig. 1 it will be seen that most of the squids in the adult Emperor penguins were immature, while most of the squids in the chicks were mature or nearly so. This surprising difference may be explained by the time of year in which the collections were made.

If Psychroteuthis glacialis is similar to many other squids in living for one year from hatching to spawning followed immediately by death, the LRL distributions seen in Fig. 1 would be expected. During the spring months of October-November, the immature growing squids which were preyed on by adult Emperors and had hatched between the previous July and September would grow almost linearly to become the population consumed in February by the Adelie penguins. These, if they continued linear growth, would become mature for the following September, when they would form the bulk of the food for the Emperor chicks at the time they spawned and died. The last to die would show in the diet of adult Emperors in late September and October to give rise to the small secondary peak of large squid in Fig. 1. In fact, all beaks in the large group were collected before October. On the other hand, in September some of the fastest growing or earliest to hatch of the recently hatched squids would be large enough to be included in the chicks' diet and would give rise to the small secondary peak of LRL in Fig. 1. 
Of the other species, most or all of the Gonatus antarcticus and the single Brachioteuthis? had darkened wings, while Kondakovia longimana, Galiteuthis glacialis and the Pholidoteuthis? had undarkened wings and were therefore immature.

\section{Discussion}

Compared with krill and fish, cephalopods are of minor importance in the diet of Emperor (Aptenodytes forsteri) and Adelie (Pygoscelis adeliae) penguins near Adelie Land during the breeding season. However, in view of the very large number of Adelie penguins in the Antarctic, the cephalopods in their diet could be of importance in estimates of cephalopod biomass. In 207 samples collected from the Ross Sea from 5 December to 5 February, Emison (1968) only found two squid beaks (Nototodarus sloani), and did not assess the weight contribution of the squid from which they came. At King George Island, South Shetlands, no squid at all was recorded in 48 samples from 1 November 1977 to 21 February 1978 (Volkmann et al., 1980).

Clearly, Psychroteuthis glacialis is taken by Emperor and Adelie penguins in far greater numbers than the other squid in this region, but the larger squid Gonatus antarcticus and Kondakovia longimana may together also be important by weight ( 31 to $47 \%$ ) in the diet of Emperor penguins.

The samples provide evidence that, near Adelie Land, Psychroteuthis glacialis probably hatches from July to September after its eggs have presumably lain dormant since the previous September. Growth is approximately linear between October and February and probably continues at a constant rate to the following September when the squids spawn and die.

The regular occurrence of Psychroteuthis glacialis in Adelie penguins from Adelie Land only after the 25 January is interesting. In February, these squids were present in $35 \%$ of the samples and contributed to $6 \%$ of the weight of the diet of Pygoscelis adeliae. These squids always occurred in samples containing numerous euphausiids. Adelie penguins did not show any major discontinuity in their diet (mainly euphausiids - Offredo, in preparation) during the collection period. Even at the end of the breeding season, their feeding behaviour changed little, so that the sudden appearance of squids in their diet may have resulted from an important change in the life of the squids themselves.

One explanation for the sudden appearance of Psychroteuthis glacialis in the Adelie diet could be that, in January, in the stronger daylight of midsummer, squids probably migrate to greater depths out of reach of the penguins; in February, their appearance in the diet of Adelies could be due to their subsequent movement to shallower depths as the autumn approaches.

On the other hand we might expect Psychroteuthis glacialis to feed on krill. The youngest stages would be unable to feed on adult krill until they grew to a sufficient body size, which they perhaps reach in February. They might then "migrate" into adult krill swarms, where they are then caught by Adelie penguins.

In February, squid predation by Adelie penguins may be locally important; data for the Indian sector of the Antarctic coast is necessary to assess the overall effects on cephalopod biomass.

Although Emperor penguins individually eat much more squid than do Adelie penguins, their wider foraging range and their smaller number (3000 pairs at Pointe Géologie in 1982) probably make their predation on the squid biomass in this area relatively minor. The deeper diving range of the Emperor penguin (down to $265 \mathrm{~m}$ : Kooyman, 1975), may explain the greater diversity of cephalopods in its diet.

Acknowledgements. The authors would like to express their thanks to the "Expéditions Polaires Francaises" for their logistical support, to the "Comite National Francais de Recherche Antarctique" for its financial contribution to the work, and to Mrs S. Marriott for typing the manuscript.

\section{Literature cited}

Clarke, M. R.: Cephalopods in the diet of sperm whales of the southern hemisphere and their bearing on sperm whale biology. 'Discovery' Rep. 37, 1-324 (1980)

Clarke, M. R.: Cephalopod biomass - estimation from predation. Mem. Nat. Mus. Vict. 44, 95-107 (1983)

Clarke, M. R. (Ed.): A handbook for the identification of cephalopod beaks, Oxford: University Press (In press) 1985

Emison, W. B.: Feeding preferences of the Adelie penguin at Cape Crozier, Ross Island. Antarctic Res. Ser. 12, 191-212 (1968)

Filippova, J. A.: New data on the squids (Cephalopoda: Oegopsida) from the Scotia Sea (Antarctic). Malacologia 11, 391-406 (1972)

Kooyman, G. L.: Behaviour and physiology of diving. In: The biology of penguins, pp 115-137. Ed. by B. Stonehouse. London: Macmillan 1975

Mougin, J.-L. et J. Prévost: Evolution annuelle des effectifs et des biomasses des oiseaux antarctiques. Terre Vie 34, 101-133 (1980)

Prévost, J.: Population, biomass and energy requirements of Antarctic birds. In: Biological investigations of marine antarctic systems and stocks (BIOMASS). Vol. 11. Selected contributions to the Woods Hole Conference on Living Resources of the Southern Ocean 1976, pp 125-137. Ed. by S. Z. EI-Sayed. Cambridge: SpecialCommittee on Antarctic Research(S.C.A.R.), International Council of Scientific Unions 1981

Roper, C. F. E.: Systematics and zoogeography of the worldwide bathypelagic squid Bathyteuthis (Cephalopoda: Oegopsida). Bull. U.S. natn. Mus. 291, 1-210 (1969)

Stonehouse, B.: The general biology and thermal balances of penguins. In: Advances in ecological research, pp 131-196. Ed. by J. B. Cragg. London: Academic Press 1967

Volkmann, J., P. Presler and W. Trievelpiece: Diets of pygoscelid penguins at King George island, Antarctica. Condor 82, 373-378 (1980)

Date of final manuscript acceptance: January 29, 1985.

Communicated by J. Mauchline, Oban 